\title{
Work Engagement: The Creation and Validation of a New Measure
}

\author{
Angus C.H. Kuok ${ }^{1}$ and Robert J. Taormina ${ }^{1}$ \\ ${ }^{1}$ University of Macau
}

\begin{abstract}
Ninety-four full-time employees were surveyed for their work engagement in Macau, China. A newly created work engagement measure with three dimensions, i.e., Cognitive, Emotional, and Physical Work Engagement, was tested for its validity and reliability. Divergent validity was tested with burnout, and convergent validity was tested with another work engagement scale. Significant correlations in the expected directions supported the validity of the new scales. Concurrent validity was established by the "known-groups" method, in which the two groups' mean scores were significantly different in the predicted directions. The new scales also had very good reliabilities, which ranged from .85 to .88 .
\end{abstract}

Keywords: Work Engagement, Cognitive, Emotional, Physical, Burnout

\section{Introduction}

The existing theories of work engagement have not been fully developed. Generally, work engagement is a state in which employees feel a sense of enjoyment in their work, are full of energy, and manage their work actively. Unfortunately, the work engagement concept has not been clearly explained in the literature. Thomas [1] recently pointed out that the term "work engagement" has been used in quite different ways by different writers, and therefore remains fairly vague.

This study takes a positive psychology point of view, which is a new trend in studying organizational behavior [2]. This approach is used here because organizational psychology has been dominated by negative terminology for a long time [3]. That is, organizations should not focus on how to manage deficits or on ways to make employees avoid the negative aspects of work, but should instead focus on the positive aspects, such as willpower and achieving goals. Therefore, work engagement represents a positive psychology that focuses on employee strengths and functioning (instead of weaknesses and malfunctioning). Furthermore, engagement can allow organizations to encourage intrinsic motivation in the workplace.

Whereas the existing theories of work engagement have different underlying ideas, this made it difficult to develop an effective way to measure work engagement. Therefore, the main objective of this study was to develop a new measure for work engagement; and there were two supplemental objectives, namely, to assess the validity and reliability of the new measure.

\section{Theoretical Background}

The two most influential existing theories of work engagement had conflicting conceptualizations. One, by Kahn [4], who first conceived of work engagement, saw it as a unipolar concept. The other main theory, by Maslach, Schaufeli, and Leiter [5], saw it as bipolar. Kahn [4] saw work engagement as the "harnessing of organizational members' selves to their work roles; in engagement, people employ and express themselves physically, cognitively, and emotionally during role performances" (p. 694), i.e., people bring their personal selves into their work. He also thought that people may disengage themselves from their work, and defined this as the "uncoupling of selves from work roles; in disengagement, people withdraw and defend themselves physically, cognitively, and emotionally during role performances" [4] (p. 694); that is, people could also leave their personal selves out of their work.

Kahn [4] explained that employees could involve themselves physically, cognitively, and emotionally during role performances at different levels, i.e., their involvement can range from being disengaged (low level) to fully engaged (high level). Thus, Kahn [4] argued that engagement at work is a variable that can have high or low levels, i.e., work engagement is a single dimension along one continuum, i.e., it is a unipolar dimension.

The other approach, by Maslach, Schaufeli, and Leiter [5], viewed work engagement as the opposite of burnout, such that they put work engagement on one end and burnout on the other end of a bipolar dimension. Furthermore, in their view, engaged employees have a positive affective-motivational state, but employees with burnout have a negative emotional state/experience at work. This theory indicates that there is either burnout or engagement (but not both), which makes it a mutually-exclusive bipolar dimension.

In the present study, in order to create a valid measure, Kahn's [4] concept of work engagement was adopted. That is, it used the idea that people bring their personal selves into their tasks physically, cognitively, and emotionally. This clarifies the work engagement concept as having three components, namely, Cognitive Work Engagement; Emotional Work Engagement; and Physical Work Engagement. 


\section{Measure Development and Research Plan}

To create a valid measure, it is necessary to have operational definitions of the concepts, and this was done here as follows. Cognitive Work Engagement is defined as the intentional and actively focused awareness of one's tasks, objectives, or organizational activities that is characterized by willingly calling one's attention to and having positive thoughts about the job, with the purpose of improving one's effectiveness at those tasks, objectives, or activities.

Emotional Work Engagement is defined as the willing attachment to tasks, objectives, or organizational activities, characterized by having positive feelings, such as pride, enthusiasm, and excitement, about actively executing and completing those tasks, objectives, or activities.

Physical Work Engagement is defined as the bodily involvement in tasks, objectives, or organizational activities by intentionally and voluntarily utilizing one's energy and effort to execute and complete those tasks, objectives, or activities.

Using these definitions, items were created from the theoretical literature, which was done in order to build the content validity of the scales. This resulted in a set of 10 items for each of the three work engagement dimensions.

The research plan was to assess the three work engagement scales for their validity and reliability. This was achieved by measuring them in conjunction with an existing work engagement scale to assess convergent validity; with a burnout scale to assess divergent validity; and with two "known groups," i.e., those already known to have either high or low work engagement (according to their work behaviors) to assess concurrent validity of the new scales.

\section{Method}

\subsection{Respondents}

Respondents were 94 (30 male, 64 female) full-time workers in Macau. Their ages were from 19 to 51 years $(\mathrm{M}=30.14, \mathrm{SD}=7.38)$. For Marital Status, 32 were single, 61 were married, and one gave no reply. For their work position, 65 were junior level, 21 were supervisorial, and 8 were managerial. Their average actual working hours/week was 42.18 ( $\mathrm{SD}=11.69)$, and contracted working hours/week was $40.86(\mathrm{SD}=4.61)$.

\subsection{Measures}

The questionnaire used contained all the variables. Except for the three newly created scales, namely, Cognitive, Emotional, and Physical Work Engagement, the measures were from existing scales with established validities and reliabilities.

As the scales were originally constructed in English, and the data were collected in Macau, where Chinese is spoken, a back-translation technique by bilingual expert linguists was used.

The study included the three newly created work engagement scales, the three components of burnout (emotional exhaustion, depersonalization, and decreased personal accomplishment), and three components of the Utrecht work engagement scale (vigor, dedication, and absorption).

The respondents were asked the extent to which they thought the statements describe them or their job, and, unless otherwise noted, all measures were scored on a 5-point Likert scale ranging from 1 (strongly disagree) to 5 (strongly agree).

Work Engagement (newly created). These variables were first assessed by 30 newly created items, i.e., 10 each for Cognitive Work Engagement (e.g., "I often think of ways to improve my work"), Emotional Work Engagement (e.g., "I undertake all of my tasks at work with great enthusiasm"), and Physical Work Engagement (e.g., "I feel energized by my work"). The reliability and the validity of these scales are discussed in the Results section.

Burnout. This variable was assessed with Maslach and Jackson's [6], 9-item Emotional Exhaustion scale (e.g., "I feel emotionally drained by my work"), 5-item Depersonalization scale (e.g., "I worry that this job is hardening me emotionally"), and 8-item Personal Accomplishment scale (e.g., "I have accomplished many worthwhile things in this job"). The reliabilities for these scales in this study were .86 for Emotional Exhaustion, .81 for Depersonalization, and .81 for Personal Accomplishment.

Utrecht Work Engagement Scales. This was evaluated using Schaufeli, Bakker, and Salanova's [7] 6-item Vigor scale (e.g., "At my work, I feel bursting with energy"), their 5-item Dedication scale (e.g., "I am enthusiastic about my job"), and their 6-item Absorption scale (e.g., "I feel happy when I am working intensely"). In this study, the reliabilities were .80 for Vigor, .85 for Dedication, and .81 for Absorption.

\subsection{Procedure}

To obtain a representative sample, data were collected in the business districts of Macau, using a randomordered sidewalk intervention technique. In accord with international guidelines for the ethical treatment of research participants, guidelines of the American Psychological Association were used.

All potential respondents were told the purpose of the study, and assured of their anonymity (because no names were recorded at any time during the study) and of the confidentiality of their data, and informed of their right to refuse to participate or to discontinue their participation at any time.

Those who agreed were handed the questionnaire, and of the 124 people asked, 94 complete questionnaires were collected, with a response rate of $75.8 \%$. 


\section{Results}

\subsection{Test of Scale Reliability}

Internal consistencies (Cronbach alphas) were computed for the three, 10-item work engagement scales. These tests required one Emotional Work Engagement item to be dropped. Hence, the reliability for Cognitive Work Engagement was .88, for Emotional Work Engagement was .88, and for Physical Work Engagement was .85 . Therefore all the scales were well above the needed .70 [8], showing very good internal consistency.

\subsection{Tests of Scale Validity}

Convergent Validity. For the first tests of validity, correlations were used. Convergent validity was found in the high positive correlations that the three dimensions of Cognitive, Emotional, and Physical Work Engagement had with all three facets of the Utrecht scale for work engagement, with all the correlations significant at the $\mathrm{p}<.001$ level.

Divergent Validity. This test assessed the three new work engagement scales' correlations with burnout. Here, the correlations should be negative; for Depersonalization and Decreased Personal Accomplishment, there were significant negative correlations with all three of the new work engagement scales. Emotional Exhaustion, though, was negatively and significantly correlated only with Emotional Work Engagement, but not with the Cognitive or Physical facets. These correlations are shown in Table 1.
Concurrent Validity. The third validity test of the new work engagement scales used the "Known Groups" method. This assesses the degree to which the measures demonstrate significantly different scores for groups that are already known to differ, and in which direction.

Thus, the questionnaires were completed by two groups of full time workers. One group was 37 teachers, professors, and doctors who were expected to be high on work engagement because they devote a great deal of effort at work, involve themselves for many hours at work, and think about their job very often. The other group was 35 casino dealers and casino floor workers who have a reputation for spending much of their time web surfing or playing with their mobile devices, and were expected to be low on work engagement as they spend little effort, thought, or emotion at work.

Then, t-tests compared the groups on the three work engagement facets, with all pairs differing significantly (at $\mathrm{p}<.001$ ) and in the expected direction. On Cognitive Work Engagement, the high work engaged employees $(M=3.79, S D=0.44)$ scored significantly higher than the low work engaged employees $(\mathrm{M}=2.72, \mathrm{SD}=0.36), \mathrm{t}(70)$ $=11.40)$. On Emotional Work Engagement, the high work engaged employees $(\mathrm{M}=3.87, \mathrm{SD}=0.46)$ scored significantly higher than the low work engaged employees $(\mathrm{M}=2.85, \mathrm{SD}=0.43), \mathrm{t}(70)=9.64$. And on Physical Work Engagement, the high work engaged employees $(\mathrm{M}=3.82, \mathrm{SD}=0.38)$ scored significantly higher than the low work engaged employees $(M=2.66$, $\mathrm{SD}=0.23)$ on, $\mathrm{t}(70)=15.53$. These results showed significant support for the concurrent validity of the three work engagement measures. See Table 2.

Table 1. Means, Standard Deviations, and correlations among the variables $(\mathrm{N}=94)$.

\begin{tabular}{lccccc}
\hline Variable & Mean & SD & CWE & EWE & PWE \\
\hline 1. Cognitive Work Engagement (CWE) & 3.33 & 0.64 & $(.88)$ & & \\
2. Emotional Work Engagement (EWE) & 3.36 & 0.62 & $.65^{* * * * *}$ & $(.88)$ & \\
3. Physical Work Engagement (PWE) & 3.27 & 0.59 & $.80^{* * * *}$ & $.78^{* * * *}$ & $(.85)$ \\
\hline 4. Emotional Exhaustion & 2.78 & 0.70 & -.03 & $-.32^{* * *}$ & -.19 \\
5. Depersonalization & 2.60 & 0.77 & $-.21^{* *}$ & $-.46^{* * * *}$ & $-.31^{* * *}$ \\
6. Decreased Personal Accomplishment & 3.41 & 0.58 & $-.56^{* * * *}$ & $-.75^{* * * *}$ & $-.64^{* * * *}$ \\
\hline 7. Vigor & 3.11 & 0.65 & $.62^{* * * * *}$ & $.69^{* * * * *}$ & $.74^{* * * * *}$ \\
8. Dedication & 3.26 & 0.78 & $.58^{* * * * *}$ & $.72^{* * * *}$ & $.71^{* * * * *}$ \\
9. Absorption & 3.18 & 0.67 & $.66^{* * * *}$ & $.66^{* * * *}$ & $.70^{* * * *}$ \\
\hline
\end{tabular}

Note. All variable values ranged from 1 (low) to 5 (high). Reliabilities are in the parentheses ( ) along the diagonal. ${ }^{*} \mathrm{p}<.05,{ }^{* *} \mathrm{p}<.01,{ }^{* * *} \mathrm{p}<.005,{ }^{* * * *} \mathrm{p}<.001$.

Table 2. Mean score t-tests on the Work Engagement Scales between high and low work engaged employees $(\mathrm{N}=72)$.

\begin{tabular}{lcccc}
\hline & $\begin{array}{c}\text { High Work Engaged } \\
(\mathrm{N}=37)\end{array}$ & $\begin{array}{c}\text { Low Work Engaged } \\
(\mathrm{N}=35)\end{array}$ & $\mathrm{t}(70)$ & $p$ \\
\hline Cognitive Work Engagement & $\begin{array}{c}3.79 \\
(S D=0.43)\end{array}$ & $\begin{array}{c}2.72 \\
(S D=0.36)\end{array}$ & 0.719 & $<.001$ \\
\hline Emotional Work Engagement & $\begin{array}{c}3.87 \\
(S D=0.46)\end{array}$ & $\begin{array}{c}2.85 \\
(S D=0.43)\end{array}$ & 0.051 & $<.001$ \\
\hline Physical Work Engagement & $\begin{array}{c}3.82 \\
(S D=0.38)\end{array}$ & $\begin{array}{c}2.66 \\
(S D=0.23)\end{array}$ & 9.938 & $<.001$ \\
\hline
\end{tabular}




\section{Discussion}

\subsection{New Measure of Work Engagement}

The results of the scale reliabilities showed that the three new work engagement measures all had excellent internal consistency, with Cognitive Work Engagement at .88, Emotional Work Engagement at .88, and Physical Work Engagement at .85.

Furthermore, the results of the three validity tests, i.e., for convergent, divergent, and concurrent validity, yielded good-to-excellent statistical support for the three new work engagement measures. The strong positive correlations that all three facets of the newly created measure had with all three parts of an existing scale gave strong support to the (convergent) validity of the new measures.

Also, the highly significant differences between the two groups who were already known to be high and low on work engagement yielded further support to the (concurrent) validity of the new work engagement measures. That is, the highly work engaged employees scored very high, while the low work engaged employees scored very low on all three facets of work engagement. In other words, highly work engaged employees have more awareness of tasks and objectives at work (cognition), have more enthusiasm and excitement about tasks at work (emotion), and voluntarily utilize their energy and effort to complete tasks at work (physical).

With regard to the test of divergent validity, the results are worth discussing. That is, it should be noted that the original concept of work engagement [4] had three facets, which formed the bases of the newly created measures. It should also be noted that the counterargument [5] viewed burnout as the opposite of work engagement, but the critical measure of burnout (i.e., Emotional Exhaustion), although negatively correlated with one of the three work engagement facets, was not significantly correlated with the other two facets. Whereas Emotional Exhaustion is the underlying construct of the Burnout measure, this could imply that burnout is not the exact opposite of Work Engagement, as proposed by Maslach et al. [5].

\section{Conclusion}

This study endeavored to clarify the concept of Work Engagement as having three facets, namely, Cognitive Work Engagement, Emotional Work Engagement, and Physical Work Engagement. The creation of these new measures and the results of the validity and reliability tests contribute to the areas of positive psychology and organizational psychology because work engagement is a new trend in studying the positive side of organizational behavior. That is, the measures help to gain more understanding of the meaning and effects of working rather than studying the negative aspects of psychology at work. In other words, traditional burnout theory typically focused on burnout itself and what caused employee burnout [9], but the emerging concept of work engagement provides a new way to improve the working situation.

Furthermore, this study also added knowledge to work engagement theory applied to Chinese society. The majority of studies on work engagement have been conducted mainly in western societies [5], [10], but, until now, there has been limited research on Chinese work engagement [11]. Therefore, the new work engagement scale can provide more insights for scholars in organizational behavior, as well as for managers, especially in the area of human resources.

\section{References}

[1] K.W. Thomas, "Intrinsic motivation at work," San Francisco, US: Berrett-Koehler, 2009.

[2] F. Luthans, and B.J. Avolio, "The "point" of positive organizational behavior," Journal of Organizational Behavior, 30(1), pp. 291-307, 2009.

[3] M.E.P. Seligman, and M. Csikszentmihalyi, "Positive psychology: An introduction," American Psychologist, 55(1), pp. 5-14, 2000.

[4] W.A. Kahn, "Psychological conditions of personal engagement and disengagement at work," Academy of Management Journal, 33(4), pp. 692-724, 1990.

[5] C. Maslach, W.B. Schaufeli, and M.P. Leiter, "Job burnout," Annual Review of Psycholology, 52(1), pp. 397-422, 2001.

[6] C. Maslach, and S.E. Jackson, "Maslach Burnout Inventory Manual, (2nd ed.)," Palo Alto, CA: Consulting Psychologists Press, 1981.

[7] W.B. Schaufeli, A.B. Bakker, and M. Salanova, "The measurement of work engagement with a short questionnaire: A cross-national study," Educational and Psychological Measurement, 66(4), pp. 701-716, 2006.

[8] J.C. Nunnally, "Psychometric theory," New York: McGraw-Hill, 1978.

[9] C. Maslach, and J. Goldberg, "Prevention of burnout: New perspectives," Applied and Preventive Psychology, 7(1), pp. 63-74, 1998.

[10] A.M. Saks, "Antecedents and consequences of employee engagement," Journal of Managerial Psychology, 21(7), pp. 600-619, 2006.

[11] Y. Zhang, and Y. Gan, "The Chinese version of Utrecht work engagement scale: An examination of reliability and validity," Chinese Journal of Clinical Psychology, 13(3), pp. 268-270, 2005. 